\title{
Effects of Tristetraprolin on Doxorubicin (Adriamycin)-induced experimental nephrotic syndrome though inhibiting IL-13 /STAT6 signal pathway
}

\section{Qian Zhang}

Zhengzhou University First Affiliated Hospital

\section{Ge Wu}

Zhengzhou University First Affiliated Hospital

\section{Shiyuan Guo}

Zhengzhou University First Affiliated Hospital

\section{Yong Liu}

Zhengzhou University First Affiliated Hospital

Zhangsuo Liu ( $D$ zhsliu2009@126.com )

Zhengzhou University First Affiliated Hospital https://orcid.org/0000-0002-9779-2264

\section{Research article}

Keywords: Nephrotic syndrome, Tristetraprolin, Doxorubicin, IL-13/STAT6 pathway

Posted Date: December 7th, 2019

DOI: https://doi.org/10.21203/rs.2.18174/v1

License: (c) (i) This work is licensed under a Creative Commons Attribution 4.0 International License.

Read Full License 


\section{Abstract}

Background: To study the effects of Tristetraprolin (TTP) on Doxorubicin (DOX)-induced experimental kidney injury (KI).

Methods: DOX was used to induce kidney injury in Balb/c male mice (in vivo) and in human kidney proximal tubular epithelial cell line (HK-2) and normal rat kidney epithelial cell line (NRK-52E) (in vitro). Body weight of the animal groups under investigation were recorded daily throughout the experimental period. Histological changes were observed using Hematoxylin-eosin (HE) staining, and levels of blood urea nitrogen, serum creatinine and serum cystatin $\mathrm{C}$ in KI mice, and ROS, MDA, LDH and SOD in cells were detected using the corresponding kits. Meanwhile, intracellular levels of oxidative stress were assessed using 2, 7-dichlorodihydrofluorescein diacetate (DCF-DA) fluorescent staining. TTP and Kim-1 expression levels were measured by immunohistochemistry and western blot. The TNF-a, IL-1 $\beta$ and IL- 6 levels were evaluated by ELISA. Expressions of IL-13, STAT6, p-STAT6, Bcl-2, Bax, cleaved-caspase3 were detected via western blot, respectively. CCK-8 was conducted for analyzing cell viability, and cells apoptosis were assessed by DAPI staining and flow cytometry.

Results: DOX treatment decreased body weight and aggravated renal injury without changes in water and food intake. DOX significantly reduced TTP expression, stimulated IL-13/STAT6 pathway and elevated the levels of several factors related to renal injury, including inflammatory response, oxidative stress and cell apoptosis, which were significantly restored by the treatment of overexpression TTP in vitro.

Conclusion: Overexpression of TTP significantly reduces DOX-induced adverse outcomes so as to prevent renal injury. Inhibition of IL-13/STAT6 pathway may be the functional mechanism under TTP in experimental KI.

\section{Background}

Nephrotic syndrome (NS), accompaning by kidney injury, is one of the primary glomerulonephritis conditions, which is characterized by proteinuria and generalized edema, oxidative stress, chronic inflammation [1]. NS will eventually develop into renal failure with no timely prevention and treatment methods. Thus, it is imperative to identify an effective therapeutic target.

RNA-binding protein tristetraprolin (TTP) is encoded by Zfp36 gene, and plays a critical role in regulating proinflammatory immune responses by destabilizing target mRNAs via binding to their AU-rich elements (AREs) within the 3 ' untranslated region (3'-UTRs) [2]. When encountering inflammatory activators, TTP expression is alleviated by TTP phosphorylation [3], allowing for the increase in TNF-a mRNAs copies. As a direct consequence of its role as a suppressor of inflammatory signaling, loss of TTP in mice results in the elevated levels of circulating cytokines and chronic inflammation [4]. Most of the characterized suppressor functions of TTP have been associated with its known target genes, including inflammatory cytokines, such as IL-8, IL-6 and IL-23 [5-7]. In glioma, it is evidenced that interleukin-13 (IL-13) is responsible for migration and invasion of glioma cells, which is equipped with ARE in the 3 '-UTR, 
providing the possibility that TTP inhibits cell invasion and metastasis by degrading IL-13 posttranscriptionally [8]. TTP also suppresses hematopoietic cell growth and induces cell apoptosis. In leukemia, the expression of TTP is obviously decreased, which leads to an explosive increase in vast proto-oncogenes, including c-Myc, Bcl-2 and IL-23 [9, 10]. Interleukins, like IL-4, can phosphorylate and activate STAT6 to modulate gene transcription, thereby IL-4/STAT6 signaling induces TTP expression and inhibits TNF-a production in mast cells [11]. Signal transducer and activator of transcription 6 (STAT6) is a latent cytoplasmic protein that is transported into the nucleus when it is activated and phosphorylated (p)-STAT6. In the nucleus, it regulates gene expression in various cell types to mediate many pathologic features of lung inflammatory responses in animal models including airway eosinophilia, epithelial mucus production, smooth muscle changes, and Th2 cell differentiation [12]. STAT6 is a key downstream protein of the IL-4/IL-13 signaling pathway in lung inflammation $[12,13]$. The IL-13/STAT6 signaling pathway is involved in airway inflammation and mucus hypersecretion [14]. However, there is rare data about the roles of TTP and IL-13/STAT6 signaling pathway in experimental renal disease.

Doxorubicin (DOX) consists of a water-insoluble planar four-ring anthracycline linked to the water-soluble sugar daunosamin. DOX may also be biotransformed to a free radical, which may directly produce toxic effects or which may, in turn, react rapidly with oxygen to produce superoxide, causing oxidative stress and ultimately cell death [15]. The exact mechanism of DOX-induced toxicity remains unclear. Some researchers have proposed that DOX-induced toxicity is most likely mediated by the formation of an ironanthracycline complex that generates reactive oxygen species (ROS) $[16,17]$. Previous studies in animals have indicated that DOX causes a renal toxicity and produces progressive glomerular injuries [15]. To study the functions of TTP in the progression of NS, Balb/c mice were treated with DOX as a vivo model, and human kidney proximal tubular epithelial cell (HK-2) and normal rat kidney epithelial cell (NRK-52E) induced with DOX were used as vitro models.

The aim of present study was to investigate the precise mechanism and exact effects of TTP in DOXinduced NS, excavating methods for ameliorations in an experimental renal disease.

\section{Methods}

\section{Animals}

Male Balb/c mice (6-8 weeks old; weighing 20-25 g) were purchased from the Laboratory Animal Center of Henan Province (Zhengzhou, China). Mice were housed under standard laboratory conditions at constant temperature of $24 \pm 2^{\circ} \mathrm{C}$ and relative humidity of $55 \pm 5 \%$ with a $12 \mathrm{~h}$ of light/dark rhythm with free access to water and diet. The present study was approved by the Ethics Committee of The First Affiliated Hospital of Zhengzhou University (China). All experimental protocols conducted in the mice were carried out in accordance with the Guide for the Care and Use of Laboratory Animals by the National Institutes of Health.

\section{Experimental Protocol}


Mice were randomly assigned into two groups: control group $(n=10)$ and DOX group $(n=10)$. Mice in DOX group received intraperitoneal (i.p.) injection with a final dose of doxorubicin ( $5 \mathrm{mg} / \mathrm{kg}$ dissolved in $0.9 \%$ normal saline) every other day for 2 weeks. Control mice received the same volume of normal saline. Before sacrifice, the body weight of all mice was recorded daily throughout the experimental period (14 days). Mice were then sacrificed under anesthesia with i.p. injection of sodium pentobarbital $(50 \mathrm{mg} / \mathrm{kg})$ on day 15.

\section{Blood samples and renal tissues collection}

All mice were euthanatized by anesthesia, and blood samples and renal tissues were collected, respectively. Blood samples from the abdominal aorta were then centrifuged at $3500 \mathrm{rpm}$ at $4^{\circ} \mathrm{C}$ for 15 min to obtain the serum for biochemical analysis. Renal tissues from mice were divided into two parts. One part was fixed in $10 \%$ neutral formalin phosphate buffer for HE staining and immunohistochemistry analysis, and the other was quickly frozen in liquid nitrogen and stored at $-80^{\circ} \mathrm{C}$ for ELISA and western blot analysis or as a backup.

\section{Detection of serum biochemical parameters}

Blood urea nitrogen (BUN), serum creatinine (Scr) and serum cystatin C (CYS-C) levels in serum of mice were assessed according to instructions of assay kits.

\section{HE staining of renal tissues}

The renal tissue samples were collected and fixed in $4 \%$ paraformaldehyde buffer (Sigma). Following dehydration in an ascending series of ethanol $(70 \%, 80 \%, 96 \%, 100 \%)$, tissue samples were cleared in xylene and embedded in paraffin. The 5 - $\mu \mathrm{m}$ thick sections were stained with $0.5 \%$ hematoxylin-eosin (HE). The morphological changes in the kidney were blindly evaluated under a light microscope (TE2000, Nikon, Japan).

\section{Immunohistochemistry analysis}

Similar to HE staining, the tissues were fixed into paraffin and next cut into paraffin-embedded renal sections using a microtome. The tissue sections $(5 \mu \mathrm{m})$ were then dewaxed, rehydrated and subjected to antigen retrieval in $0.01 \mathrm{M}$ citrate buffer $(\mathrm{pH} 6.0)$ in a microwave oven. After washing with PBS, the sections were prepared for blocking and incubating with primary antibodies against TTP and kidney injury molecule-1(Kim-1) overnight and detected by the biotin-labeled secondary antibody. The bound antibodies were visualized by DAB staining and imaged using a light microscope (TE2000, Nikon, Japan). Brown staining in the cytoplasm and/or nucleus was considered as an indicator of positive expression.

\section{Cell culture and treatment}

The human kidney proximal tubular epithelial cell (HK-2) line and normal rat kidney epithelial cell (NRK$52 \mathrm{E})$ line were purchased from the cell bank of Chinese Academy of Sciences (China). Cells were cultured 
in RPMI 1640 supplemented with 10\% fetal bovine serum (FBS, Sigma), $100 \mathrm{U} / \mathrm{ml}$ penicillin and 100 $\mu \mathrm{g} / \mathrm{ml}$ streptomycin. To mimic nephropathy in vitro, HK-2 and NRK-52E cells at $80 \%$ confluence were treated with various doses of DOX dissolved in dimethyl sulfoxide (DMSO) $(0,1,3,5,7$ and $10 \mu \mathrm{M})$ for 24 h. Next, cell viability was assessed after treatment with different doses of DOX to verify the most appropriate DOX dose for the subsequent experiments (cell activity was above $50 \%$ with relatively lowdose of $5 \mu \mathrm{M}$ DOX).

\section{Cell transfection and grouping}

According to cell viability, $5 \mu \mathrm{M}$ of DOX were chosen to induce cells, which presented that cell activity was above $50 \%$ with relatively low-dose. The overexpression-TTP or negative control (NC) plasmids were transfected into HK2 and NRK-52E cells with Lipofectamine 2000 (Invitrogen). Twenty-four hours after transfection, cells were divided into the following groups: (1) control group, cells were treated with solvent (DMSO); (2) DOX group, cells were treated with $5 \mu \mathrm{M}$ of DOX; (3) overexpression-NC group, cells were transfected with overexpression-NC after treating with $5 \mu \mathrm{M}$ of DOX; (4) overexpression-TTP, cells were transfected with overexpression-TTP after treating with $5 \mu \mathrm{M}$ of DOX; (5) overexpression-TTP+IL-13 group, cells were transfected with overexpression-TTP and treated with IL-13 $(10 \mathrm{ng} / \mathrm{ml})$ after treating with $5 \mu \mathrm{M}$ of DOX.

\section{Cell viability assay}

The viability of HK2 and NRK-52E cells was determined using the Cell Counting Kit-8 (CCK-8) according to the manufacturer's instructions. Briefly, cells were seeded in 96-well plates at a density of $2.5 \times 10^{4}$ cells/well. Different concentrations of $\operatorname{DOX}(0,1,3,5,7$ and $10 \mu \mathrm{M}$ for $24 \mathrm{~h})$ were used in the present study before the CCK-8 assay. Additionally, after transfection, cells were incubated for 24,48 , and $72 \mathrm{~h}$. Subsequently, $10 \mu \mathrm{l}$ of CCK-8 solution was added to the cells for $4 \mathrm{~h}$ of incubation at $37^{\circ} \mathrm{C}$, and the OD values resulting from CCK-8 staining were measured using a microplate reader at a wavelength in the $450 \mathrm{~nm}$ (CCK-8), which indirectly reflects the viabilities of cells.

\section{Enzyme-linked immunosorbent assay (ELISA)}

The levels of TNF-a, IL-1 $\beta$ and IL- 6 in mice serums, renal tissue homogenate and cells supernatant were determined by the ELISA, using the TNF-a, IL-1 $\beta$ and IL-6 ELISA kits (R\&D, Minneapolis) following the manufacturer's instructions. Briefly, samples were placed in 96-well plates and incubated for $1 \mathrm{~h}$ at $37^{\circ} \mathrm{C}$ with biotin-conjugated antibodies targeting TNF-a, IL-1 $\beta$ and IL-6, followed by culture with enzymatic working solution for $30 \mathrm{~min}$ at $37^{\circ} \mathrm{C}$. The absorbance at $450 \mathrm{~nm}$ were finally detected for quantitation of protein abundances.

\section{Detection of MDA, LDH and ROS contents and SOD activity}

The level of superoxide dismutase (SOD) activity indirectly reflects the ability of the body to scavenge reactive oxygen species (ROS), while the level of malondialdehyde (MDA) indirectly reflects the severity of 
cells attacked by ROS. When the cell membrane damages, lactate dehydrogenase (LDH) is rapidly released. So, we determined the degree of cell damage by detecting LDH activity in cell culture supernatant. HK2 and NRK-52E cells were collected for preparing cell supernatant samples. The samples were added to 96-well culture dishes and measured with commercial assay kits for MDA, LDH, ROS and SOD, respectively as described [18].

\section{Detection of intracellular ROS level}

The intracellular ROS levels were detected using 2, 7-dichlorodihydrofluorescein diacetate (DCF-DA) staining. DCFH-DA has no fluorescence and is hydrolyzed into DCFH (dichlorodihydrofluorescein) by esterase after entering the cell. In the presence of ROS, DCFH is oxidized to the enhanced green fluorescent substance DCF that cannot penetrate the cell membrane, and its fluorescence intensity is directly proportional to the level of intracellular ROS. Briefly, $10 \mu \mathrm{M}$ of DCF-DA was added into the medium, the HK2 and NRK-52E cells were incubated for $1 \mathrm{~h}$ at $37^{\circ} \mathrm{C}$ in the dark. After DCF-DA staining, ROS generation in cells was also observed under a fluorescence microscopy (Olympus).

\section{DAPI staining assay by confocal microscope}

After treatments, the HK2 and NRK-52E cells in 6-well plates were fixed with $4 \%$ formaldehyde at room temperature for 20 min and then were stained with DAPI $(5 \mu \mathrm{M})$. The DAPI-stained cells were observed with a fluorescence microscope (magnification, $\times 100$ ) for estimation of the percentage of cells not undergoing apoptosis.

\section{Cell apoptosis assay}

After treatments, the HK2 and NRK-52E cells were cultured until cell confluence reached $80 \%$. Next, cells seeded in 6-well plate were harvested and washed twice with PBS. Annexin V-FITC (5 $\mu$ l) and PI (5 $\mu \mathrm{l})$ were added to the samples and incubated at room temperature for $10 \mathrm{~min}$ in the dark, and then samples were processed immediately in a BD FACS flow cytometry (BD Biosciences, USA).

\section{Western blot assay}

Total protein was extracted from renal tissues, HK2 or NRK-52E cells by using the RIPA lysate and the protein concentration was measured using the BCA method. Protein samples $(20 \mu \mathrm{g})$ were respectively separated on $10 \%$ or $12 \%$ SDS polyacrylamide gel for electrophoresis, and then electrophoretically transferred onto a PVDF membrane. Thereafter, the PVDF membrane was hybridized in blocking buffer overnight at $4^{\circ} \mathrm{C}$ together with primary antibodies, including Tristetraprolin (71632;1:1000;Cell Signaling Technology, Inc.), Kim-1 (ab78494; 1:1000; Abcam), TNF-a (3707;1:1000;Cell Signaling Technology, Inc.), IL-1 $\beta$ (12242;1:1000;Cell Signaling Technology, Inc.), IL-6 (12912;1:1000;Cell Signaling Technology, Inc.), IL-13 (ab106732; 1:1000; Abcam), p-STAT6 (56554;1:1000;Cell Signaling Technology, Inc.), STAT6 (5397;1:1000;Cell Signaling Technology, Inc.), cleaved-caspase3 (9661;1:1000;Cell Signaling Technology, Inc.), caspase3 (9662;1:1000;Cell Signaling Technology, Inc.), Bax (ab32503; 1:1,000; Abcam) and Bcl-2 (ab32124; 1:1,000; Abcam). On the next day, the membranes were washed with PBS for 8 mins ${ }^{\star} 5$ times; 
then the membranes were probed by incubation with a secondary antibody for $2 \mathrm{~h}$ at room temperature and washed with PBS for 7 mins $* 6$ times before exposure. Finally, the membranes were exposed to ECL chemiluminescence solution and imaged by using a Tanon 4500 System (Tanon, Shanghai, China). All proteins expression were analyzed as described [19] and GAPDH was used as the loading control.

\section{RT-qPCR}

Total RNA was isolated from the HK2 and NRK-52E cells, according to the instructions provided by the manufacturer, using TRIzol reagent (Invitrogen). Subsequently, cDNA was synthesized from RNA (10 $\mu$ l) through a reverse transcriptase reaction using the First Strand cDNA synthesis kit (Invitrogen). To quantify the relative mRNA expression of Tristetraprolin (Zfp36 gene), the primers were synthesized following, forward 5'-GACTGAGCTATGTCGGACCTT-3', and reverse 5'-GAGTTCCGTCTTGTATTTGGGG-3', with GAPDH used as the endogenous control. Real-time PCR was performed using the qPCR SYBR Green Mix (Bio-Rad, Hercules, USA) on an AB 7300 Real time PCR system. Quantitative PCR results were calculated using the $2^{-\triangle \Delta C t}$ method.

\section{Statistical analysis}

Data were expressed as the means \pm standard deviation (SD) and analyzed using SPSS 13.0 software (IBM). The differences between groups were analyzed by one-way analysis of variance (ANOVA), and the differences between the two groups were determined by Student's t-test followed by post hoc Dunnett's test. The correlations between variables were examined using Pearson's correlation coefficient. Differences with $p<0.05$ were considered statistically significant.

\section{Results}

\section{Doxorubicin (DOX) induced the changes of body weight, histological morphology of renal tissue and serum biochemical parameters in DOX mice.}

Mice in the DOX model group lost a significant amount of weight during the course of the experiment, in comparison with control group (Figure $1 a, p<0.05$ and $p<0.01$ ). Figures $1 b$ showed results of histological examination of renal tissues from normal mice and DOX-induced mice. Compared with the control group, section of renal tissue from the DOX group exhibited tubular brush-border loss, interstitial edema, necrosis of epithelium, as well as hyaline casts, glomeruli adhere to glomerular cysts, tubular vacuoles and protein casts. In addition, serum biochemical parameters were also examined. Serum urea nitrogen creatinine and cystatin $\mathrm{C}$ levels were significantly higher in DOX-induced mice than those in control mice (Figure $1 c-e, p<0.01$ and $p<0.001$ ).

\section{TTP and Kim-1 expressions in renal tissues}

Western blot and immunohistochemically staining demonstrated that DOX induced a significant decrease in the expression of TTP and a dramatic increase in the expression of Kim-1, a marker protein of renal 
injury, in kidney tissue in comparison to those of the control group (Figure $2 a$ and $2 b, p<0.05$ and $p<0.01$ ). Based on these data, the correlation between TTP and Kim-1 was analyzed using Pearson's correlation coefficient analysis and a significantly negative correlation was found (Figure $2 c, R^{2}=0.7907$ ), indicating that TTP might be negatively related to renal injury.

\section{DOX induced an increase in the expression of inflammatory factors and IL-13/STAT6 pathway genes in renal tissue, and serum cytokines containing TNF- $\alpha$, IL-1 $\beta$ and IL- 6}

In the renal tissue, the protein expressions of TNF- $a, \mathrm{IL}-1 \beta$ and IL- 6 , three inflammatory factors, were notably increased in the mice predisposed with DOX compared with those in control mice (Figure 3a, $p<0.05$ and $p<0.001)$. As shown in Figure $3 b, D O X$ also significantly enhanced the levels of three serum cytokines: TNF-a, IL-1 $\beta$ and IL- 6 (vs. the control group, $p<0.001$ ). In addition, western blot results of IL13/STAT6 pathway-related proteins in renal tissues were presented in Figure 3c. DOX-induced mice had significantly higher protein expressions of IL-13 and p-STAT6 compared to those in control mice $(p<0.01$ and $p<0.001)$.

\section{Effects of different doses of DOX treatment on the expression of TTP and cell viability in HK-2 and NRK- 52E cells}

Western blot and RT-qPCR results indicated that different doses of DOX $(0,1,3,5,7$ and $10 \mu \mathrm{M}$ for $24 \mathrm{~h})$ distinctly reduced TTP expression both in HK-2 (Figure 4a) and NRK-52E (Figure 4b) cells, hinting the inhibitory impact of DOX on TTP in a dose-dependent manner. Similarly, cell viability of HK-2 (Figure 4c) and NRK-52E (Figure 4d) cells was remarkably weakened after DOX treatment, and this decrease was strengthened with increasing dose. Due to the above finding that cell viability was decreased to near $50 \%$ and TTP expression decreased significantly $(p<0.001)$ under DOX treatment at the dose of $5 \mu \mathrm{M}$, we chosen DOX at the dose of $5 \mu \mathrm{M}$ (for $24 \mathrm{~h}$ ) for subsequent experiments.

\section{Effect of TTP on cell viability}

After transfection with overexpression-TTP or overexpression-NC, western blot and RT-qPCR were performed to confirm the transfection efficiency in HK-2 and NRK-52E cell lines. The protein and mRNA expression of TTP in HK-2 and NRK-52E cells was obviously improved after 24-h overexpression-TTP transfection under DOX treatment (Figure $5 a$ and $5 b ; p<0.01$ and $p<0.001$ ). Interestingly, overexpression of TTP could elevate the decreased viability of HK-2 and NRK-52E cells caused by DOX treatment (Figure $5 c$ and $5 d ; p<0.01$ at $48 \mathrm{~h}$ and $p<0.001$ at $72 \mathrm{~h}$ ), indicating that existence of TTP was beneficial to cell survival.

\section{Effect of TTP on IL-13/STAT6 signal pathway}

Western blot revealed that DOX treatment markedly increased IL-13 and p-STAT6 expressions in HK-2 and NRK-52E cells, compared with control cells (Figure $6 a$ and $6 b, p<0.001$ ), and TTP overexpression could reduce DOX-promoted IL-13 and p-STAT 6 expressions (Figure 6a and 6b; $p<0.01$ and $p<0.001$ ). However, 
IL-13 and p-STAT6 expressions were up-regulated in in HK-2 cells after addition of IL-13 (10 ng/ml) compared with overexpression-TTP group (Figure 6a; $\mathrm{p}<0.01$ ). Meanwhile, IL-13 treatment raised IL-13 expression (Figure $6 b ; p<0.05$ ) and also induced p-STAT6 expression (Figure 6b; $p>0.05$ ) in NRK-52E cells compared with overexpression-TTP group. There was no significant differences of total (t)-STAT6 expression under these treatments.

\section{Effects of TTP on pro-inflammatory and oxidative stress}

Compared with negative control group, pro-inflammatory factors (TNF-a, IL-1 $\beta$ and IL-6) levels in HK-2 and NRK-52E cells were significantly high in DOX group (Figure $6 \mathrm{c}$ and $6 d, p<0.001$ ). Besides, TTP overexpression induced obvious decrease in TNF- $a$, IL-1 $\beta$ and IL-6 levels compared to DOX+overexpression-NC group (Figure $6 c$ and $6 d, p<0.001$ ). These changes were reversed when cells were added with IL-13 ( $p<0.001)$.

Additionally, DOX-induced group presented distinct elevations in the levels of oxidative stress markers (ROS, MDA and LDH) and a sharp decrease in SOD level in HK-2 and NRK-52E cells compared to control cells (Figure 7a and 7b; $p<0.001$ ). Moreover, transfection with overexpression-TTP resulted in significant attenuations of the ROS, MDA and LDH levels $(p<0.001)$ but a significant rise of SOD level $(p<0.001)$ in both HK-2 and NRK-52E cells compared to those in DOX+overexpression-NC group. Subsequently, administration of IL-13 $(10 \mathrm{ng} / \mathrm{ml})$ rescued the variations of ROS, MDA, LDH and SOD levels in HK-2 and NRK-52E cells in contrast with overexpression-TTP group (Figure 7a and 7b; $p<0.001$ ).

More convincingly, the presence of DCF-DA-positive cells confirmed the formation of ROS in HK-2 and NRK-52E cells with DOX-induced oxidative damage. Treatment with DOX significantly elevated DCF-DA fluorescence in HK-2 (Figure 7c) and NRK-52E (Figure 7d) cells compared to those in control group. Under treatment with DOX, the DCF-DA fluorescence was significantly lessened through enhancement of TTP. Notably, treatment with IL-13 induced a significant increase in ROS formation (DCF-DA fluorescence) in TTP-overexpressed cells exposed to DOX (Figure 7c and 7d).

\section{Effects of TTP on cell apoptosis and apoptotic markers}

After staining with DAPI, the morphology of the nuclei of HK-2 and NRK-52E cells was presented (Figure $8 \mathrm{a}$ and $8 \mathrm{~b})$. Chromatin condensation and nuclear fragmentation of cells were considered as indications of the induction of apoptosis. In the control group, the nuclei were uniformly distributed with normal morphology, but a dramatic decrease in the number of nucleus (blue dots) appeared in the DOX groups. Fortunately, these were ameliorated to some degree after cells were transfected with overexpression-TTP, suggesting that TTP could alleviate cell apoptosis in vitro. However, IL-13 treatment could stimulate cell apoptosis as aforementioned with a decrease in the number of DAPI cyanotic cells both in HK-2 and NRK52E cells (Figure 8a and 8b).

The cell apoptosis was measured using flow cytometry by analyzing the percentage of cells in the third quadrant (Q3). As shown in Figure 8c (HK-2 cells) and 8d (NRK-52E cells), in the control group, the cells 
were normal, and the apoptosis rate was very small. The apoptosis rate increased significantly after DOX treatment $(p<0.001)$. In contrast, transfection with overexpression-TTP reduced the apoptosis rate significantly $(p<0.001)$. The apoptosis rate in the overexpression-TTP+IL-13 group also increased when compared with that in the overexpression-TTP group $(p<0.001)$.

In order to determine the anti-apoptotic effect of TTP, our study detected the expression of anti-apoptotic protein (Bcl-2) and pro-apoptotic proteins (Bax and Caspase3). As shown in Figure 9a and 9b, western blot results revealed that after treatment with DOX, the expression of Bax and Cleaved-caspase 3 were increased and the expression of Bcl-2 was decreased significantly in both HK-2 and NRK-52E cells $(p<0.001)$. Meanwhile, overexpression TTP could suppress the increase of Bax and Cleaved-caspase3 and the decrease of Bcl-2 noticeably when compared with DOX+overexpression-NC group $(\mathrm{p}<0.01$ and $\mathrm{p}<0.001)$. Compared with overexpression-TTP group, treatment with IL-13 reduced the expression of Bcl-2 significantly and up-regulated the expression of Bax and Cleaved-caspase 3 in HK-2 cells $(p<0.05, p<0.01$ and $p<0.001)$. In addition, IL-13 addition elevated the Bax expression significantly in NRK-52E cells $(p<0.05)$, with no significant effects on the expression of $B c l-2$ and Cleaved-caspase $3(p>0.05)$ comparing to overexpression-TTP group. However, no statistically significant difference was observed in the caspase 3 expression among these five groups.

\section{Discussion}

A classical nephrotic syndrome (NS) model [20], with the treatment of DOX, is used in the present study. Administration of DOX caused significant reduction in body weight of model mice, which might be due to either decrease food intake or the mobilization and utilization of fat [21]. Also, in the DOX-induced group, the significant increases in BUN, Scr and CYS-C suggested impairment of the kidney function, which coincides with Alimba et al. who has reported that significantly increased proteinuria are essential for the diagnosis of NS [22]. In this study, we also found DOX significantly stimulated the excretion of serum TNF- $\alpha$, IL-1 $\beta$ and IL- 6 , and their up-regulated expression in the kidney injury mice. Consistent with our findings, previous studies have shown that Huang Qi Huai (HQH) granules prevent podocyte injury in kidney injury rats by inhibition of expression of the pro-inflammatory cytokines, such as IL-1 $\beta$ and TNF- $a$, etc. [23]. The anti-inflammatory molecule TTP can limit the expression of a number of critical genes for chronic inflammatory diseases and cancers [24]. The kidney injury molecule-1(Kim-1) is a sensitive and valuable classic biomarker for renal damage [25], and its overexpression is an intermediate step in the sequence of progression from primary tubular activation to end-stage tubulointerstitial damage [26]. Consistent with these studies, in vivo experiments demonstrated a significant elevation of Kim-1 in DOXtreated mice with a striking decrease of TTP compared to normal rats from the western blot quantification and immunohistological localization. Additionally, there was a significant negative correlation between Kim-1 and TTP. The above studies indicated that TTP played an important role in maintaining the normal morphology of renal tubular cells and retaining normal kidney function.

TTP expression was also significantly decreased in cell experiments when the human kidney proximal tubular epithelial cells (HK-2) and normal rat kidney epithelial cells (NRK-52E) were stimulated by DOX. 
We used different doses of DOX to stimulate the two cell lines and found that TTP expression gradually decreased with the increase of dose of DOX), and the cell activity also decreased gradually, which also indicated that TTP had a positive effect on maintaining normal cell activity. A relative low dose of DOX dose at $5 \mu \mathrm{M}$ (above $50 \%$ cell viability) was selected for subsequent experiments. Due to the assumption of the positive effect of TTP on cell activity in NS mice, we overexpressed TTP in cell models in vitro. In this experiment, TTP overexpression could restore cell viability that was inhibited by DOX induction.

TTP, one of the best characterized RNA-binding proteins, is important in inhibiting the expression of proinflammatory cytokines in macrophages. A study has shown that TTP suppresses IL-27 production by targeting the p28 mRNA for degradation, resulting in suppression of CD8 T-cell functions [27]. In glioma, TTP exerts tumor suppressive functions on the tumorigenesis of glioma by targeting downstream gene IL-13 [28]. Th2 cytokines, including IL-4, IL-5, IL-10, IL-13, are implicated in frequent relapses of NS in minimal change disease (MCNS) [29], and raised level of IL-13 is found in NS and has a role in the pathogenesis of disease [30]. STAT6, a critical transcription factor activated in response to IL-13 [31], becomes phosphorylated at its conserved tyrosine residue $Y 641$, and dimerizes and translocates into the nucleus where it induces the transcription of target genes [32]. The STAT6 mRNA expression was significantly increased and correlated with early unfavorable course of NS in children [33], and STAT6 genes may be associated with predisposition to MCNS [34, 35]. In human epithelial cells from airway, esophagus and intestine, the regulation of eotaxin-3 expression by IL-13 has been shown to require STAT6 activation [36]. IL-13 exposure causes STAT6 activation in up to one third of minimal change disease patients [37]. The above studies suggest that IL-13/STAT6 signaling pathway may play a key role in NS. Similar to these results, we found that the IL-13/STAT6 signaling pathway was activated both in vivo and in vitro, and that IL-13 promoted STAT6 phosphorylation and nuclear translocation to aggravate kidney injury. What was interesting was that after TTP was overexpressed in vitro cell model (both in HK-2 and NRK-52E cells), the IL-13/STAT6 signaling was inhibited, which was restored after IL-13 resupplementation. These findings firstly indicated that TTP probably negatively regulated the downstream $\mathrm{IL}-13$ signaling pathway and played a protective role in $\mathrm{KI}$.

Inflammation and apoptosis contribute to the pathogenesis of many diseases, renal diseases contained [38]. Meanwhile, we also observed increased expression of pro-inflammatory cytokines (TNF-a, IL-1 $\beta$ and IL-6) both in vivo and in vitro. After TTP overexpression was administered in vitro, decreased proinflammatory cytokines and pro-apoptotic factors (Bax and Cleaved-caspase3) were observed, whereas the expression of anti-apoptotic protein (Bcl-2) was increased. However, after IL-13 was added to the cells for activation of the IL-13/STAT6 signaling pathway, the levels of inflammation and cell apoptosis were significantly strengthened, indicating that the IL-13/STAT6 signaling pathway might be involved in the regulation of inflammation and apoptosis in kidney injury. The results of DAPI staining and flow cytometry in our study also validated this conclusion.

In the same manner, to explore the antioxidation of TTP in the DOX-induced toxicity in cells, we analyzed the ROS generation, MDA and LDH content, and SOD activity using kits and DCF-DA fluorescent staining. ROS are highly reactive free radicals and induce the oxidative reaction of cellular lipids, proteins and 
nucleic acids, and cell death due to disruption of the intracellular redox balance [39]. ROS has been postulated to explain the underlying mechanisms of DOX-induced nephropathy [40]. MDA is selected as a typical oxidative marker of the peroxidation of polyunsaturated fatty acids [41] and the LDH release is used to value the integrity of the cell membrane [42]. SOD is known as one of the crucial enzymatic antioxidant defenses against superoxide radicals, whose activity is decreased in disorders of resistance to oxidative stress [43]. In consistent with these data, we found out enhanced redox state in HK-2 and NRK-52E cells obtained from DOX group in the form of significant increases in ROS, MDA and LDH and a significant depletion in SOD. Overexpression of TTP lowered oxidative stress noticeably, while activation of IL-13/STAT6 signaling could induce excessive ROS accumulation in cells again to cause the oxidative damage.

These results indicated that TTP could alleviate cells injury in DOX-induced KI in vitro. We could conclude that the protective mechanism of TTP seemed to be realized through regulating the IL-13/ATAT6 signaling pathway. The limitation of the present study lies in the lack of intervention experiments in vivo to verify the protective effects of TTP. Based on the conclusion of this study, subsequent experiments will focus on exploring the underlying mechanism of TTP on DOX-induced KI in animals.

\section{Conclusion}

These findings for the first time suggested that TTP exhibited a significant protective effect against DOXinduced kidney injury, which might be related to the downregulation of the IL-13/STAT6 signaling pathway. The present study demonstrated that TTP significantly downregulated inflammation, apoptosis and oxidative stress, and suppressed IL-13/STAT6 signaling. Therefore, we hypothesized that TTP probably prevented renal injury via regulating the IL-13/STAT6 signaling pathway. Although more additional studies need to be perform to confirm these findings, all these findings may provide a theoretical foundation for the development of the treatment of NS.

\section{Abbreviations}

TTP: Tristetraprolin

DOX: Doxorubicin

KI: Kidney injury

HE: Hematoxylin-eosin

DCF-DA: 2, 7-dichlorodihydrofluorescein diacetate

NS: Nephrotic syndrome

AREs: AU-rich elements 
IL: Interleukin

STAT6: Signal transducer and activator of transcription 6

ROS: Reactive oxygen species

BUN: Blood urea nitrogen

Scr: Serum creatinine

CYS-C: Serum cystatin C

SOD: Superoxide dismutase

MDA: Malondialdehyde

LDH: Lactate dehydrogenase

Kim-1: Kidney injury molecule-1

MCNS: Minimal change disease

\section{Declarations}

\section{Ethics approval and consent to participate}

Not applicable.

\section{Consent for publication}

All authors signed written informed consent for publication.

\section{Availability of data and materials}

The datasets used and/or analysed during the current study are available from the corresponding author on reasonable request.

\section{Competing interests}

The authors declare that they have no competing interests.

\section{Funding}

No.

\section{Authors' contributions}


QZ and ZSL designed the study. QZ, GW and SYG performed the experiments. QZ, GW, SYG and YL analyzed the data. QZ wrote the manuscript. All authors read and approved the final manuscript.

\section{Acknowledgements}

No.

\section{References}

[1] Lu R, Zhou J, Liu B, Liang N, He Y, Bai L, Zhang P, Zhong Y, Zhou Y and Zhou J. Paeoniflorin ameliorates Adriamycin-induced nephrotic syndrome through the PPARgamma/ANGPTL4 pathway in vivo and vitro. Biomed Pharmacother 2017; 96: 137-147.

[2] Tu Y, Wu X, Yu F, Dang J, Wang J, Wei Y, Cai Z, Zhou Z, Liao W, Li L and Zhang Y. Tristetraprolin specifically regulates the expression and alternative splicing of immune response genes in HeLa cells. BMC Immunology 2019; 20:

[3] Tiedje C, Holtmann $\mathrm{H}$ and Gaestel $\mathrm{M}$. The role of mammalian MAPK signaling in regulation of cytokine mRNA stability and translation. J Interferon Cytokine Res 2014; 34: 220-232.

[4] Taylor GA, Carballo E, Lee DM, Lai WS, Thompson MJ, Patel DD, Schenkman DI, Gilkeson GS, Broxmeyer HE, Haynes BF and Blackshear PJ. A pathogenetic role for TNF alpha in the syndrome of cachexia, arthritis, and autoimmunity resulting from tristetraprolin (TTP) deficiency. Immunity 1996; 4 : 445-454.

[5] Bourcier C, Griseri P, Grepin R, Bertolotto C, Mazure N and Pages G. Constitutive ERK activity induces downregulation of tristetraprolin, a major protein controlling interleukin8/CXCL8 mRNA stability in melanoma cells. Am J Physiol Cell Physiol 2011; 301: C609-618.

[6] Van Tubergen E, Vander Broek R, Lee J, Wolf G, Carey T, Bradford C, Prince M, Kirkwood KL and D'Silva NJ. Tristetraprolin regulates interleukin-6, which is correlated with tumor progression in patients with head and neck squamous cell carcinoma. Cancer 2011; 117: 2677-2689.

[7] Lee HH, Yang SS, Vo MT, Cho WJ, Lee BJ, Leem SH, Lee SH, Cha HJ and Park JW. Tristetraprolin down-regulates IL-23 expression in colon cancer cells. Mol Cells 2013; 36: 571-576.

[8] Guo J, Qu H, Chen Y and Xia J. The role of RNA-binding protein tristetraprolin in cancer and immunity. Med Oncol 2017; 34: 196.

[9] Rounbehler RJ, Fallahi M, Yang C, Steeves MA, Li W, Doherty JR, Schaub FX, Sanduja S, Dixon DA, Blackshear PJ and Cleveland JL. Tristetraprolin impairs myc-induced lymphoma and abolishes the malignant state. Cell 2012; 150: 563-574. 
[10] Molle C, Zhang T, Ysebrant de Lendonck L, Gueydan C, Andrianne M, Sherer F, Van Simaeys G, Blackshear PJ, Leo $\mathrm{O}$ and Goriely S. Tristetraprolin regulation of interleukin 23 mRNA stability prevents a spontaneous inflammatory disease. J Exp Med 2013; 210: 1675-1684.

[11] Suzuki K, Nakajima H, Ikeda K, Maezawa Y, Suto A, Takatori H, Saito Y and Iwamoto I. IL-4-Stat6 signaling induces tristetraprolin expression and inhibits TNF-alpha production in mast cells. J Exp Med 2003; 198: 1717-1727.

[12] Walford HH and Doherty TA. STAT6 and lung inflammation. JAKSTAT 2013; 2: e25301.

[13] Liu Y, Zhang H, Ni R, Jia WQ and Wang YY. IL-4R suppresses airway inflammation in bronchial asthma by inhibiting the IL-4/STAT6 pathway. Pulm Pharmacol Ther 2017; 43: 32-38.

[14] Boucherat O, Boczkowski J, Jeannotte L and Delacourt C. Cellular and molecular mechanisms of goblet cell metaplasia in the respiratory airways. Exp Lung Res 2013; 39: 207-216.

[15] Mohamad RH, El-Bastawesy AM, Zekry ZK, Al-Mehdar HA, Al-Said MG, Aly SS, Sharawy SM and El-Merzabani MM. The role of Curcuma longa against doxorubicin (adriamycin)-induced toxicity in rats. $J$ Med Food 2009; 12: 394-402.

[16] DeGraff W, Hahn SM, Mitchell JB and Krishna MC. Free radical modes of cytotoxicity of adriamycin and streptonigrin. Biochem Pharmacol 1994; 48: 1427-1435.

[17] Lee V, Randhawa AK and Singal PK. Adriamycin-induced myocardial dysfunction in vitro is mediated by free radicals. Am J Physiol 1991; 261: H989-995.

[18] Jiang Y, Zhou Z, Meng QT, Sun Q, Su W, Lei S, Xia Z and Xia ZY. Ginsenoside Rb1 Treatment Attenuates Pulmonary Inflammatory Cytokine Release and Tissue Injury following Intestinal Ischemia Reperfusion Injury in Mice. Oxid Med Cell Longev 2015; 2015: 843721.

[19] Li H, Yao W, Irwin MG, Wang T, Wang S, Zhang L and Xia Z. Adiponectin ameliorates hyperglycemia-induced cardiac hypertrophy and dysfunction by concomitantly activating Nrf2 and Brg1. Free Radic Biol Med 2015; 84: 311-321.

[20] Barbano B, Gigante A, Amoroso A and Cianci R. Thrombosis in nephrotic syndrome. Semin Thromb Hemost 2013; 39: 469-476.

[21] Boonsanit D, Kanchanapangka S and Buranakarl C. L-carnitine ameliorates doxorubicin-induced nephrotic syndrome in rats. Nephrology (Carlton) 2006; 11: 313-320.

[22] Alimba CG, Dhillon V, Bakare AA and Fenech M. Genotoxicity and cytotoxicity of chromium, copper, manganese and lead, and their mixture in WIL2-NS human B lymphoblastoid cells is enhanced by folate depletion. Mutat Res Genet Toxicol Environ Mutagen 2016; 798-799: 35-47. 
[23] Zhu C, Huang S, Ding G, Yuan Y, Chen Q, Pan X, Chen R and Zhang A. Protective effects of Huang Qi Huai granules on adriamycin nephrosis in rats. Pediatr Nephrol 2011; 26: 905-913.

[24] Sanduja S, Blanco FF, Young LE, Kaza V and Dixon DA. The role of tristetraprolin in cancer and inflammation. Front Biosci (Landmark Ed) 2012; 17: 174-188.

[25] Vaidya VS, Ramirez V, Ichimura T, Bobadilla NA and Bonventre JV. Urinary kidney injury molecule1: a sensitive quantitative biomarker for early detection of kidney tubular injury. Am J Physiol Renal Physiol 2006; 290: F517-529.

[26] van Timmeren MM, Bakker SJ, Vaidya VS, Bailly V, Schuurs TA, Damman J, Stegeman CA, Bonventre JV and van Goor H. Tubular kidney injury molecule-1 in protein-overload nephropathy. Am J Physiol Renal Physiol 2006; 291: F456-464.

[27] Wang Q, Ning H, Peng H, Wei L, Hou R, Hoft DF and Liu J. Tristetraprolin inhibits macrophage IL27-induced activation of antitumour cytotoxic T cell responses. Nat Commun 2017; 8: 867.

[28] Zeng B, Zhu D, Su Z, Li Z and Yu Z. Tristetraprolin exerts tumor suppressive functions on the tumorigenesis of glioma by targeting IL-13. Int Immunopharmacol 2016; 39: 63-70.

[29] Stangou M, Spartalis M, Daikidou DV, Kouloukourgiotou T, Sampani E, Lambropoulou IT, Pantzaki A, Papagianni A and Efstratiadis G. Impact of Tauh1 and Tauh2 cytokines in the progression of idiopathic nephrotic syndrome due to focal segmental glomerulosclerosis and minimal change disease. $J$ Nephropathol 2017; 6: 187-195.

[30] Mishra OP, Teli AS, Singh U, Abhinay A and Prasad R. Serum immunoglobulin E and interleukin-13 levels in children with idiopathic nephrotic syndrome. J Trop Pediatr 2014; 60: 467-471.

[31] Zhou L, Kawate T, Liu X, Kim YB, Zhao Y, Feng G, Banerji J, Nash H, Whitehurst C, Jindal S, Siddiqui A, Seed B and Wolfe JL. STAT6 phosphorylation inhibitors block eotaxin-3 secretion in bronchial epithelial cells. Bioorg Med Chem 2012; 20: 750-758.

[32] Wang C, Zhu C, Wei F, Zhang L, Mo X, Feng Y, Xu J, Yuan Z, Robertson E and Cai Q. Constitutive Activation of Interleukin-13/STAT6 Contributes to Kaposi's Sarcoma-Associated Herpesvirus-Related Primary Effusion Lymphoma Cell Proliferation and Survival. J Virol 2015; 89: 10416-10426.

[33] Ostalska-Nowicka D, Smiech M, Jaroniec M, Zaorska K, Zawierucha P, Szaflarski W, Malinska A and Nowicki M. SOCS3 and SOCS5 mRNA expressions may predict initial steroid response in nephrotic syndrome children. Folia Histochem Cytobiol 2011; 49: 719-728.

[34] Kobayashi Y, Arakawa H, Suzuki M, Takizawa T, Tokuyama K and Morikawa A. Polymorphisms of interleukin-4-related genes in Japanese children with minimal change nephrotic syndrome. Am J Kidney Dis 2003; 42: 271-276. 
[35] Ikeuchi Y, Kobayashi Y, Arakawa H, Suzuki M, Tamra K and Morikawa A. Polymorphisms in interleukin-4-related genes in patients with minimal change nephrotic syndrome. Pediatr Nephrol 2009; 24: 489-495.

[36] Cheng E, Zhang X, Wilson KS, Wang DH, Park JY, Huo X, Yu C, Zhang Q, Spechler SJ and Souza RF. JAK-STAT6 Pathway Inhibitors Block Eotaxin-3 Secretion by Epithelial Cells and Fibroblasts from Esophageal Eosinophilia Patients: Promising Agents to Improve Inflammation and Prevent Fibrosis in EoE. PLoS One 2016; 11: e0157376.

[37] Kim AH, Chung JJ, Akilesh S, Koziell A, Jain S, Hodgin JB, Miller MJ, Stappenbeck TS, Miner JH and Shaw AS. B cell-derived IL-4 acts on podocytes to induce proteinuria and foot process effacement. JCI Insight 2017; 2:

[38] Stambe C, Atkins RC, Tesch GH, Kapoun AM, Hill PA, Schreiner GF and Nikolic-Paterson DJ. Blockade of p38alpha MAPK ameliorates acute inflammatory renal injury in rat anti-GBM glomerulonephritis. J Am Soc Nephrol 2003; 14: 338-351.

[39] Sinha K, Das J, Pal PB and Sil PC. Oxidative stress: the mitochondria-dependent and mitochondria-independent pathways of apoptosis. Arch Toxicol 2013; 87: 1157-1180.

[40] El-Shitany NA, El-Haggar S and El-desoky K. Silymarin prevents adriamycin-induced cardiotoxicity and nephrotoxicity in rats. Food Chem Toxicol 2008; 46: 2422-2428.

[41] Gong K and Li W. Shikonin, a Chinese plant-derived naphthoquinone, induces apoptosis in hepatocellular carcinoma cells through reactive oxygen species: A potential new treatment for hepatocellular carcinoma. Free Radic Biol Med 2011; 51: 2259-2271.

[42] Liu Q, Wang Q, Yang X, Shen X and Zhang B. Differential cytotoxic effects of denitroaristolochic acid II and aristolochic acids on renal epithelial cells. Toxicol Lett 2009; 184: 5-12.

[43] Huang P, Feng L, Oldham EA, Keating MJ and Plunkett W. Superoxide dismutase as a target for the selective killing of cancer cells. Nature 2000; 407: 390-395.

\section{Figures}




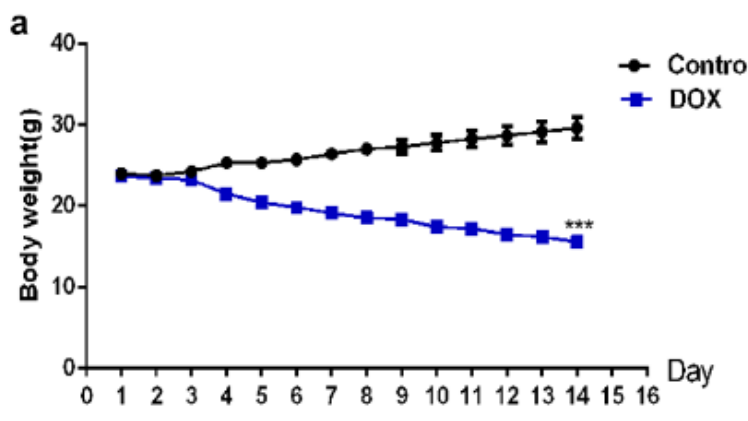

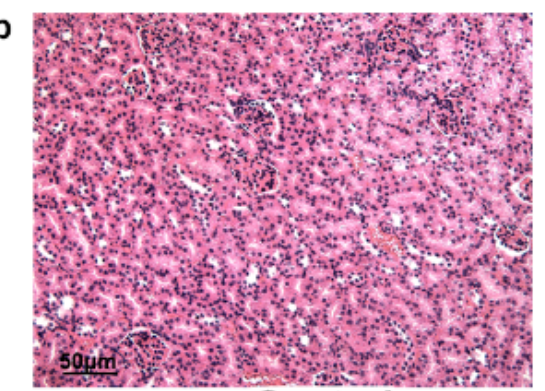

Control

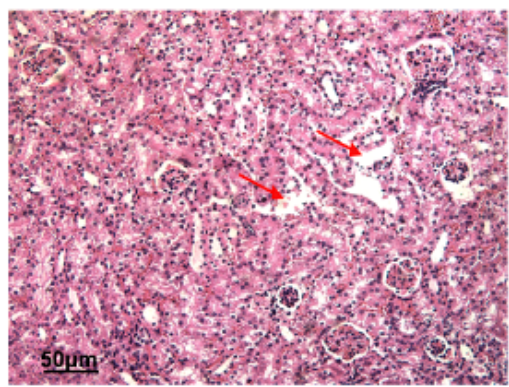

DOX
C

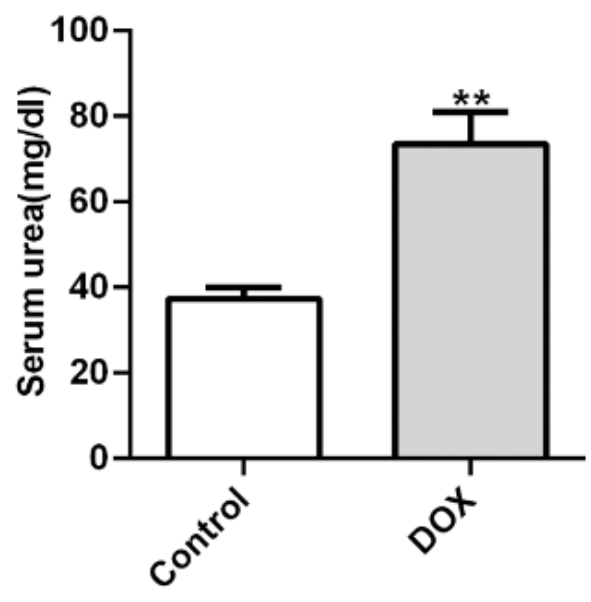

d

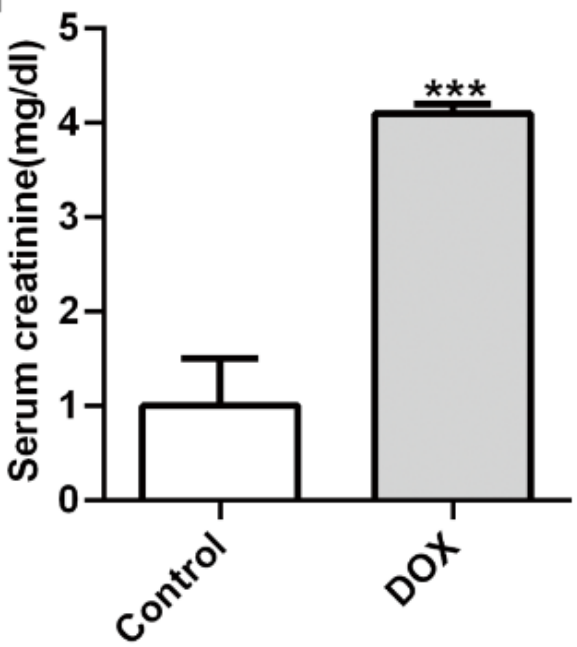

e

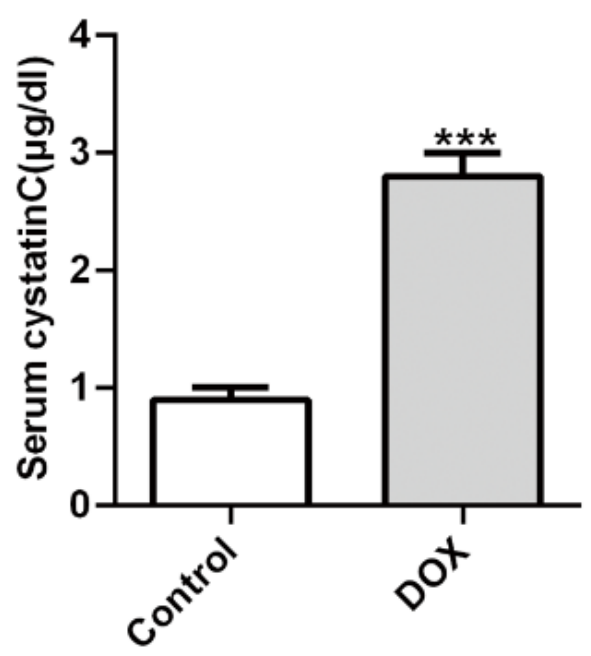

Figure 1

The body weight, morphological changes of renal tissues and serum biochemical parameters in DOXinduced mice. (a) Measurement of body weight daily throughout the experimental period (14 days) in the control and DOX groups. (b) HE-stained sections of the renal tissues in the control and DOX groups showed the condition of the structures in kidney (200x). The red arrow indicates tissue necrosis and tubular vacuoles. Bar graphs presented the actual measurements of the levels of blood urea nitrogen (BUN) (c), serum creatinine (Scr) (d) and serum cystatin C (CYS-C) (e) in the serum in the control and DOX groups (all detected by commercial kits). All values were expressed as means $\pm S D, n=10$. ${ }^{*} p<0.01$ and $\star \star \star p<0.001$ vs. Control. 

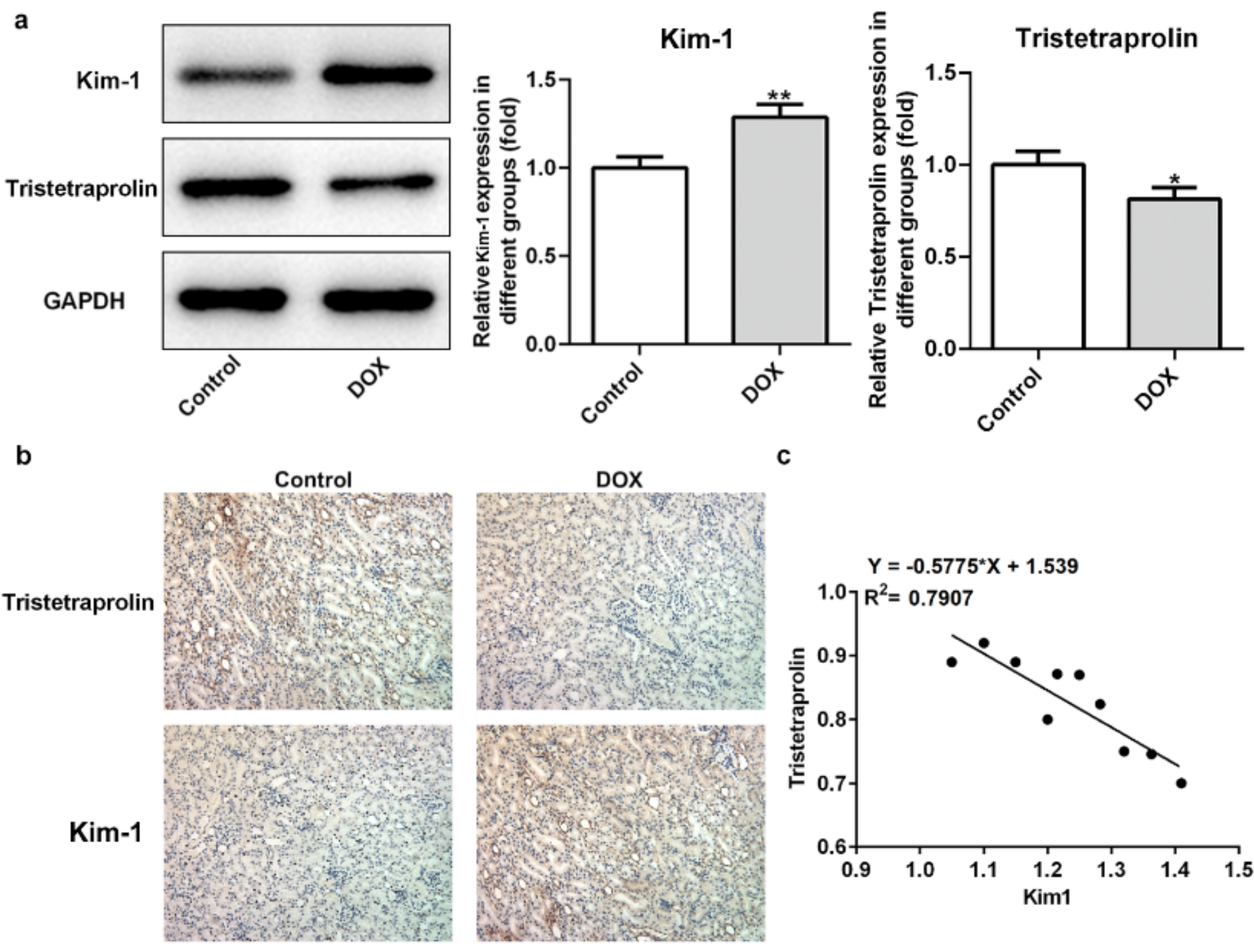

c

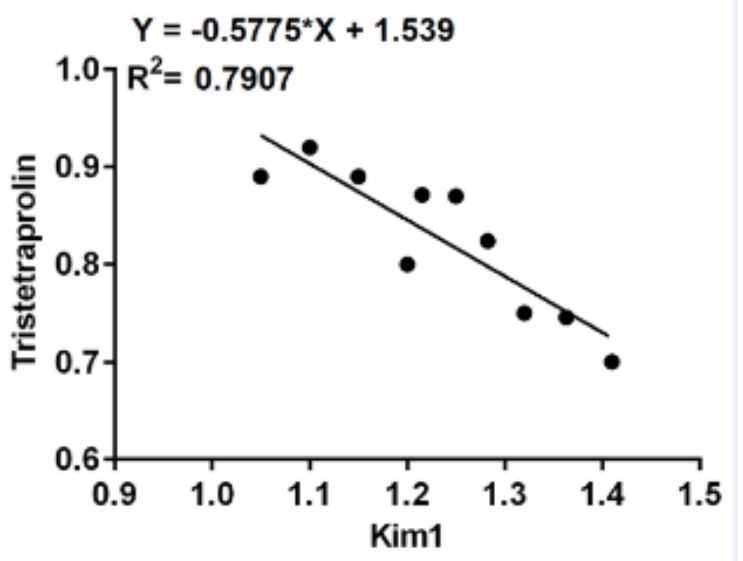

Figure 2

Expressions of Tristetraprolin (TTP) and Kim-1 in DOX-induced mice. (a) Western blot analysis for total TTP and Kim-1 and the housekeeping protein GAPDH in renal tissues. The bar graphs represented the relative expression compared to GAPDH. ${ }^{*} p<0.05$ and ${ }^{* *} p<0.01$ vs. Control. (b) Immunohistochemical staining in the renal tissues of control and DOX groups, showing the TTP and Kim-1 expression (200x). (c) Pearson's correlation coefficient analysis demonstrated a significantly negative correlation between TTP and Kim-1. R2=0.7907. All values were expressed as means $\pm S D, n=10$. 


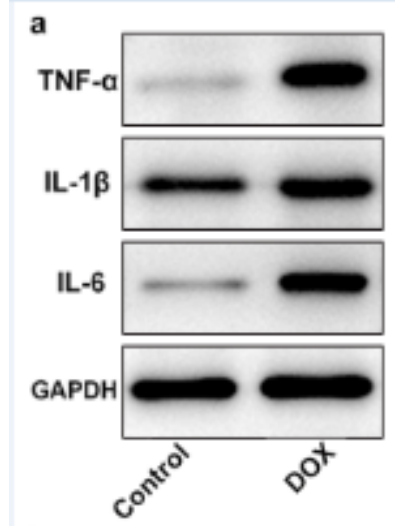

b

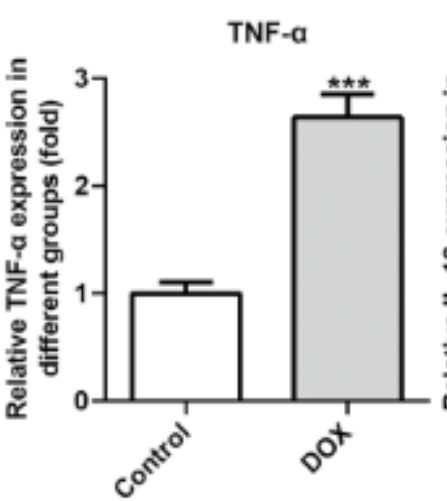

TNF-a
IL-1 $\beta$

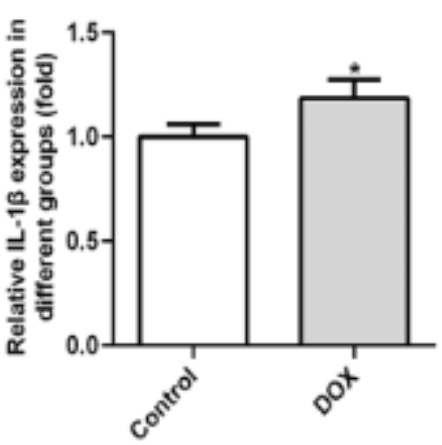

IL-1 $\beta$
IL-6

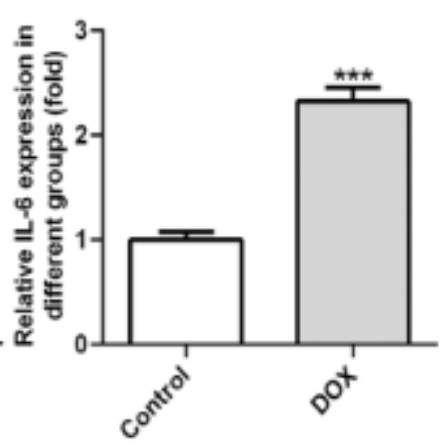

IL-6
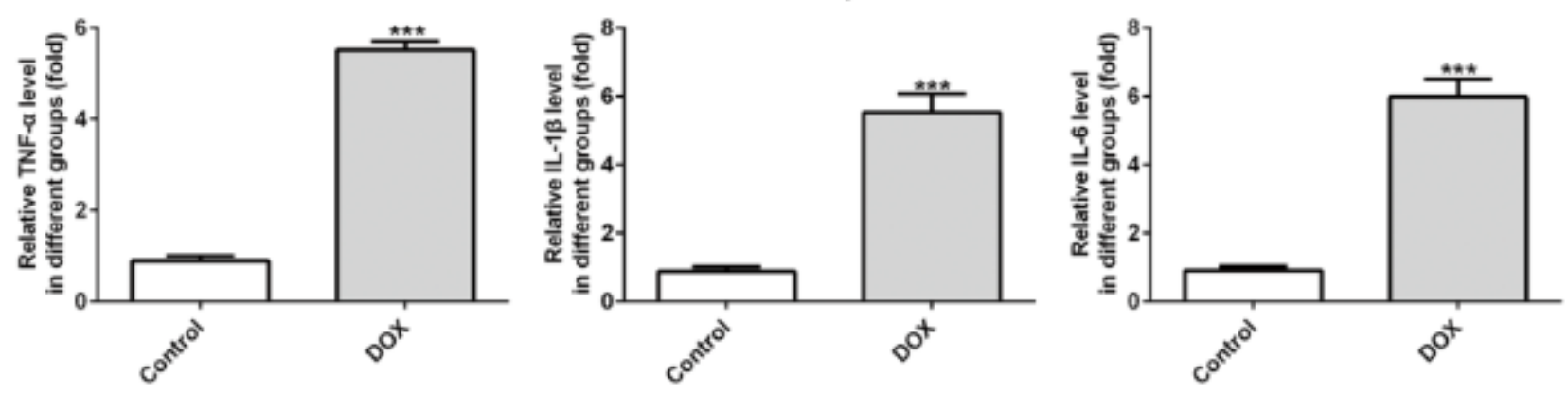

c
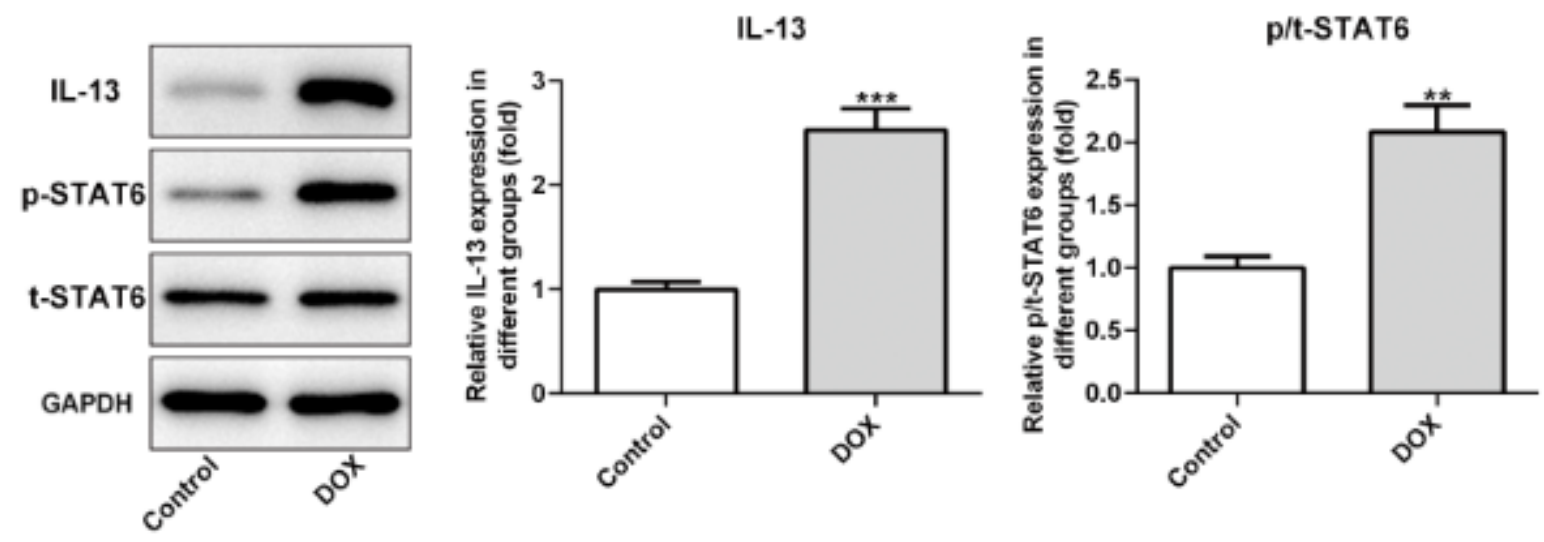

\section{Figure 3}

Levels of pro-inflammatory cytokines (TNF-a, IL-1 $\beta$ and IL-6) and IL-13/STAT6 pathway in the renal tissues and serum. (a) The protein expression of TNF-a, IL-1 $\beta$ and IL- 6 in the renal tissues was determined by western blot. Left panel: representative immunoblots. Right panel: densitometric analysis. (b) Serum levels of TNF-a, IL-1 $\beta$ and IL-6 were determined by ELISA. (c) Western blot for IL-13, phosphorylated (p)STAT6 and total (t)-STAT6 expression in renal tissues in both control and DOX groups. All values were expressed as means $\pm S D, n=10 .{ }^{*} p<0.05,{ }^{*} p<0.01$ and ${ }^{* *} p<0.001$ vs. Control. 


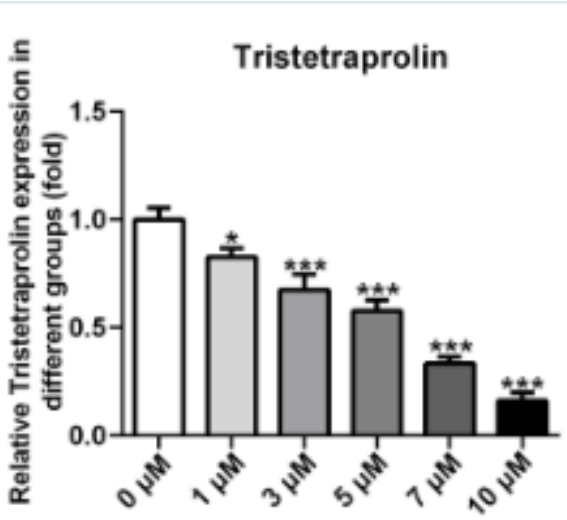

b NRK-52E
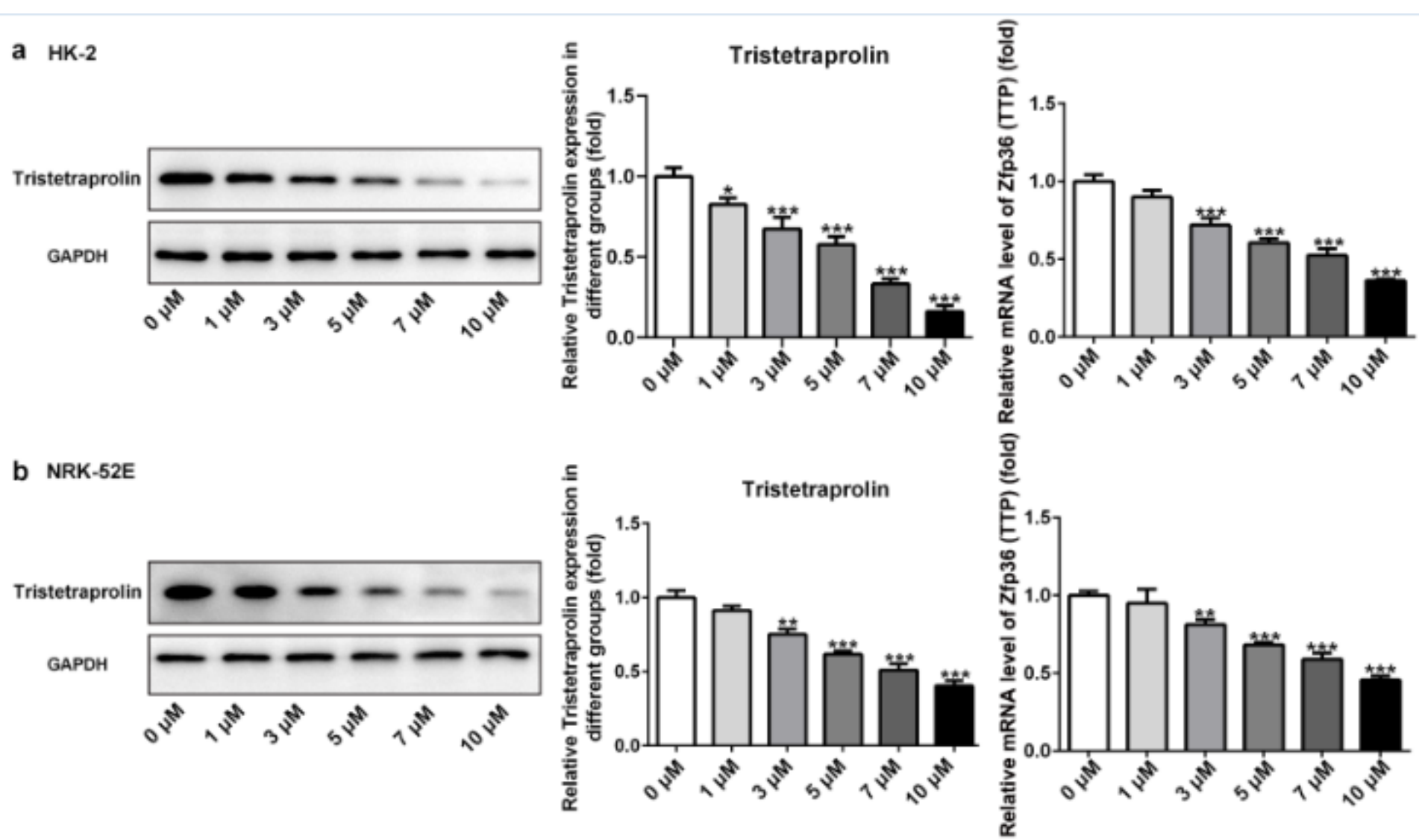

c

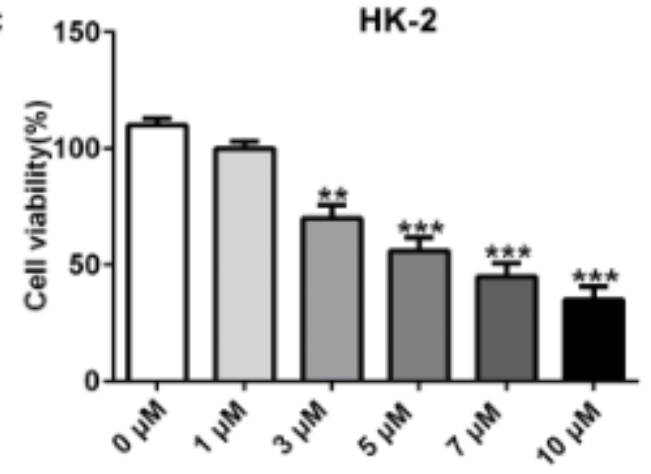

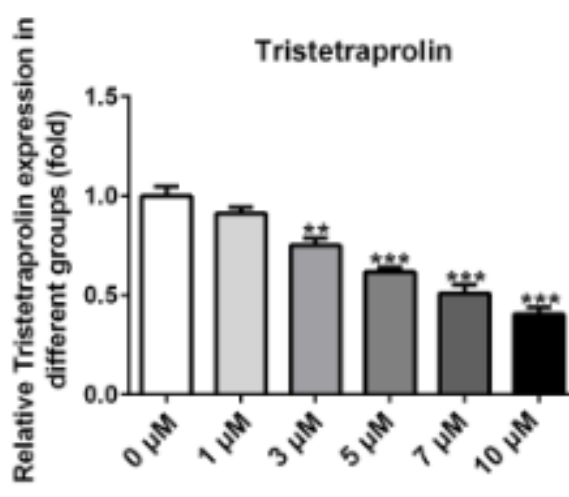

d

NRK-52E

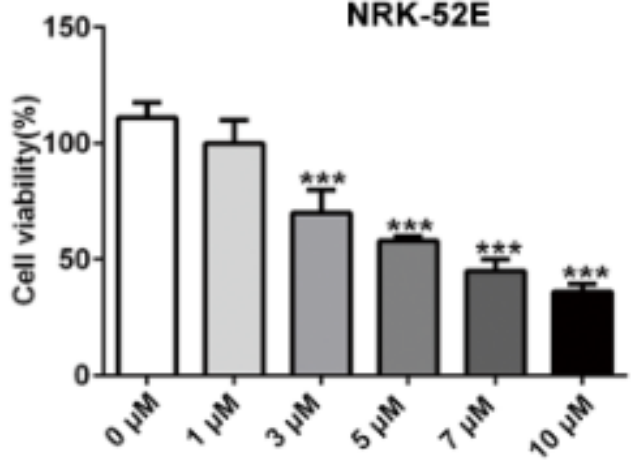

Figure 4

Expressions of Tristetraprolin (TTP) and cell viability in HK-2 and NRK-52E cells after treatment with different doses of DOX. After DOX treatment with various doses (0, 1, 3, 5, 7 and $10 \mu \mathrm{M})$, TTP protein expression and mRNA expression in (a) HK-2 cells and (b) NRK-52E cells were detected by western blot and RT-qPCR, respectively. After DOX treatment at different doses $(0,1,3,5,7,10 \mu \mathrm{M})$, cell viability of (c) HK-2 cells and (d) NRK-52E cells was assessed using CCK-8 assay. All values were expressed as means \pm SD, $n=5,{ }^{*}<<0.05,{ }^{*} p<0.01$ and ${ }^{* *} p<0.001$ vs. $0 \mu \mathrm{M}$. 


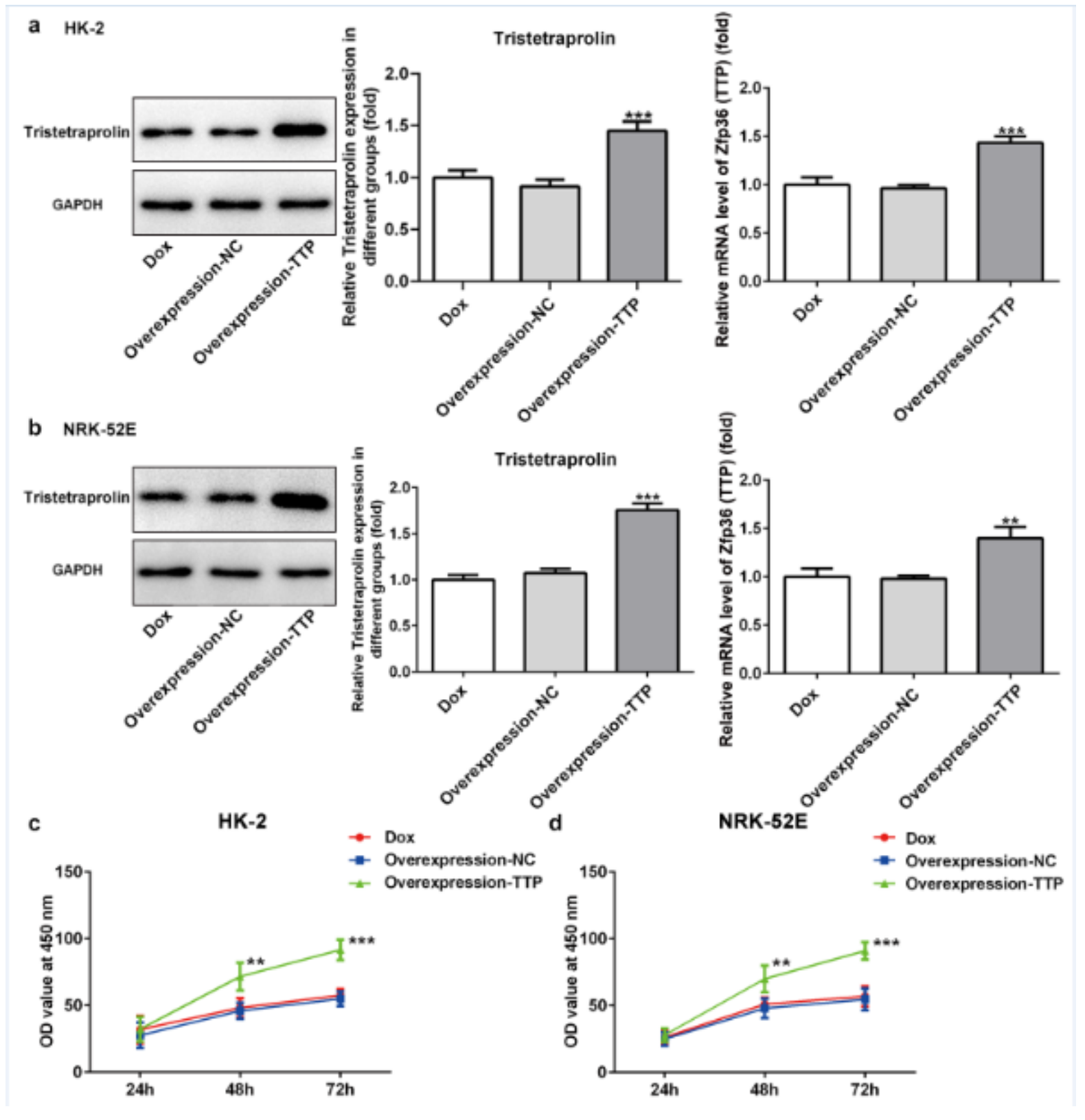

Figure 5

Effect of Tristetraprolin (TTP) on cell viability in HK-2 and NRK-52E cells after treatment with DOX. After transfection of overexpression-TTP, the expressions of TTP protein and mRNA in DOX-treated (a) HK-2 cells and (b) NRK-52E cells were detected by western blot and RT-qPCR, respectively. The cell viability of DOX-treated (c) HK-2 cells and (d) NRK-52E cells was valued by CCK-8 assay after treatment with overexpression-TTP. All values were expressed as means $\pm S D, n=5$, $* * p<0.01$ and ${ }^{* \star} p<0.001$ vs. DOX. 
a HK-2

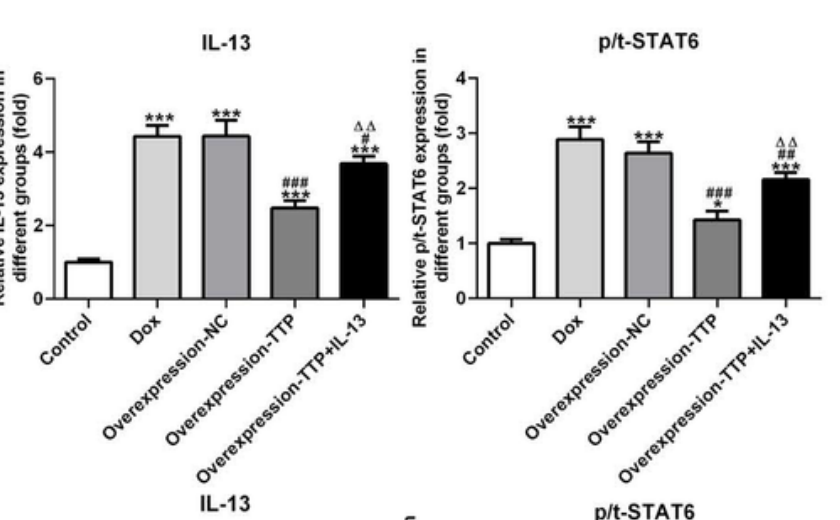

b NRK-52E
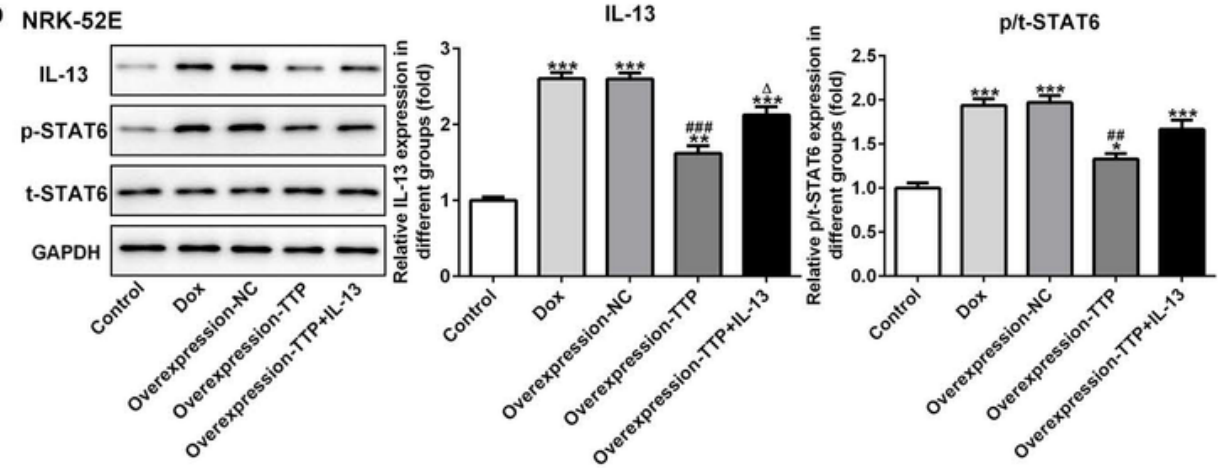

$C_{\text {HK-2 }}$ TNF-a

IL-1 $\beta$

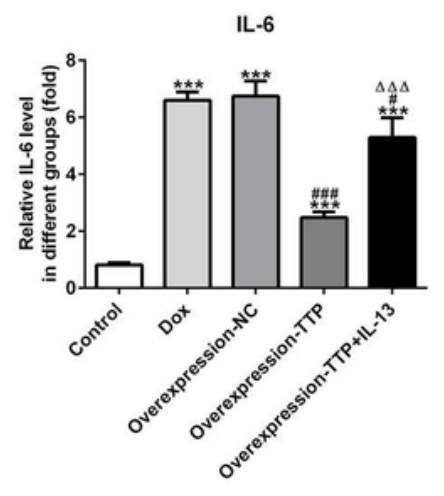

d NRK-52E TNF- $a$
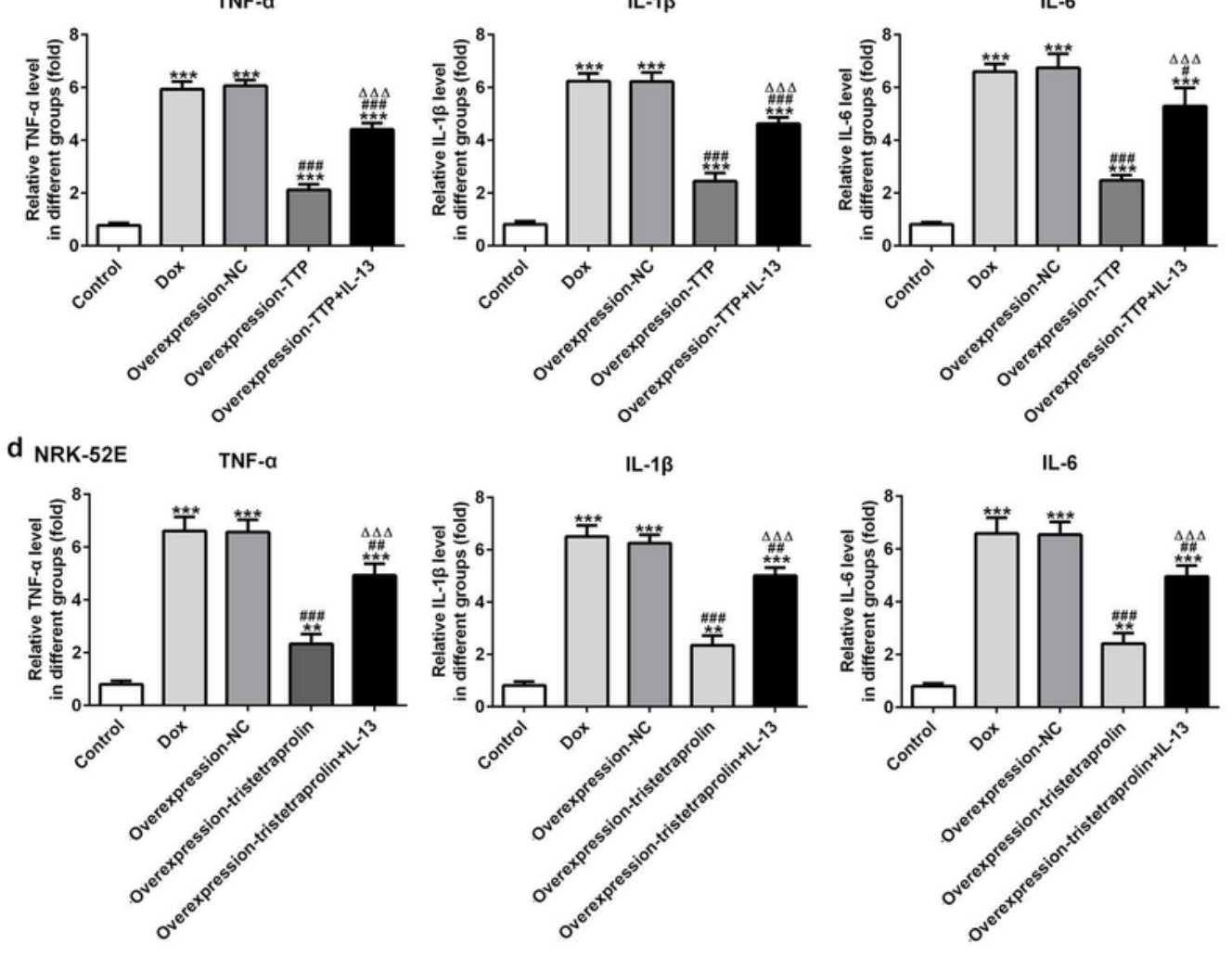

\section{Figure 6}

Effects of Tristetraprolin (TTP) on IL-13/STAT6 signaling and inflammation in HK-2 and NRK-52E cells post treatment with DOX. Western blot was carried out in (a) HK-2 and (b) NRK-52E cells of five different groups, showing the IL-13, p-STAT6 and t-STAT6 expressions. ELISA assay was used to measure the levels of TNF-a, IL-1 $\beta$ and IL-6 in (c) HK-2 and (d) NRK-52E cells of the five different groups. All values 
were expressed as means $\pm S D, n=5,{ }^{*} p<0.05,{ }^{*} p<0.01$ and $* * * p<0.001$ vs. Control; \#p<0.05, \#\#p<0.01 and \#\#\#p<0.001 vs. DOX; $\triangle p<0.05, \triangle \triangle p<0.01$ and $\triangle \triangle \triangle p<0.001$ vs. Overexpression-TTP.
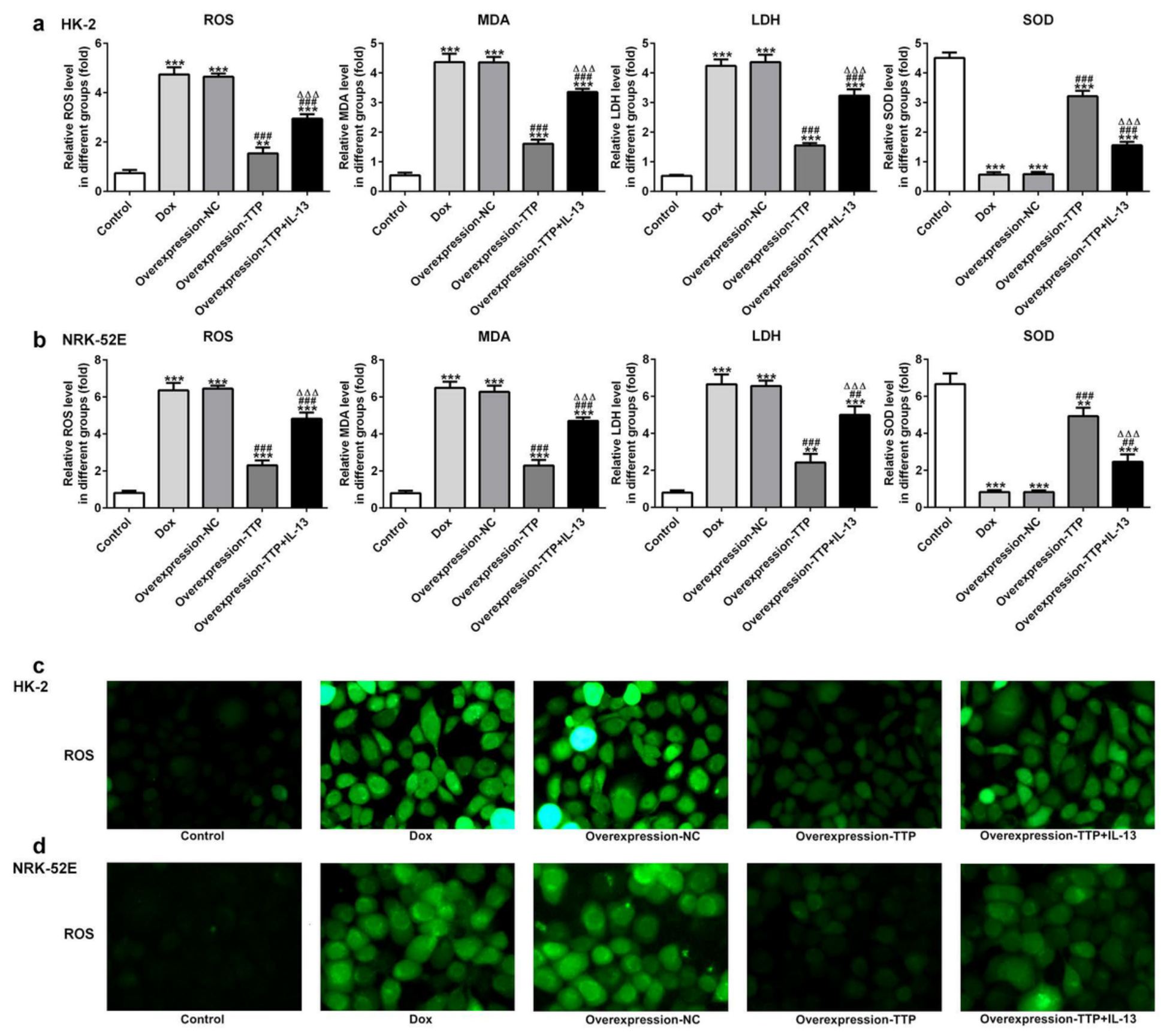

Figure 7

Effect of Tristetraprolin (TTP) on oxidative stress in HK-2 and NRK-52E cells after DOX treatment. (a) The commercial assay kits were performed to detect the levels of ROS, MDA, LDH and SOD in (a) HK-2 and (b) NRK-52E cells of the five groups. ROS generation was also observed by measuring the DCF-DA fluorescence intensity in (c) HK-2 and (d) NRK-52E cells under a fluorescence microscope at 200x magnification after same treatments as previously described. All values were expressed as means $\pm S D$,

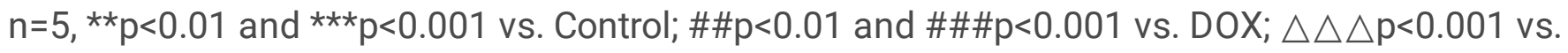
Overexpression-TTP. 
HK-2

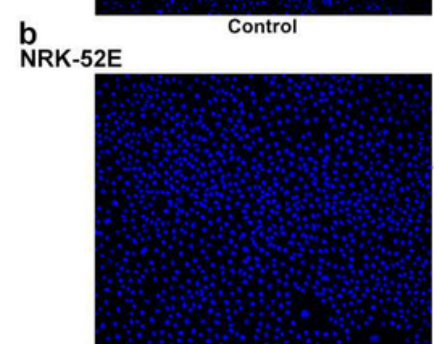

Control

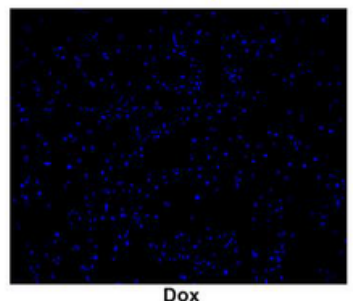

Dox

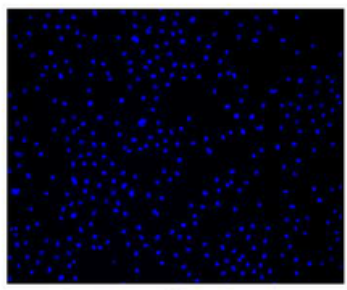

Dox

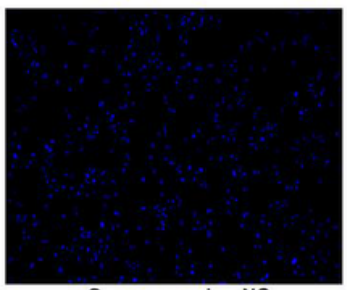

Overexpression-NC

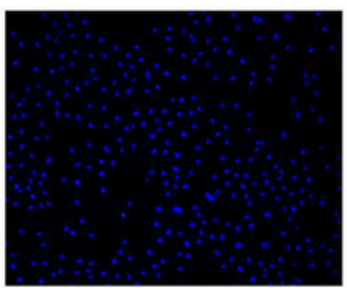
Overexpression-NC

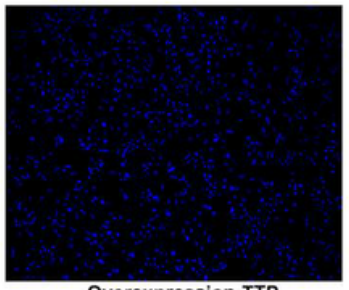

Overexpression-TTP

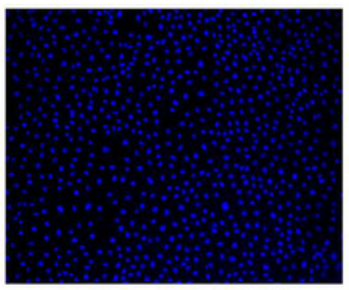

Overexpression-TTP

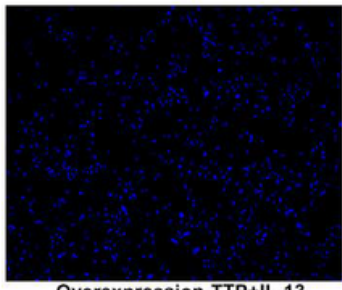

Overexpression-TTP+IL-13

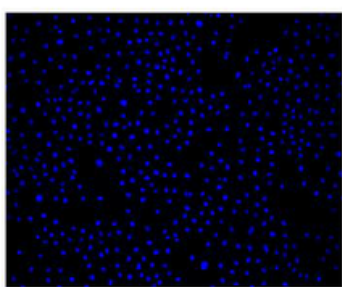

Overexpression-TTP+IL-13
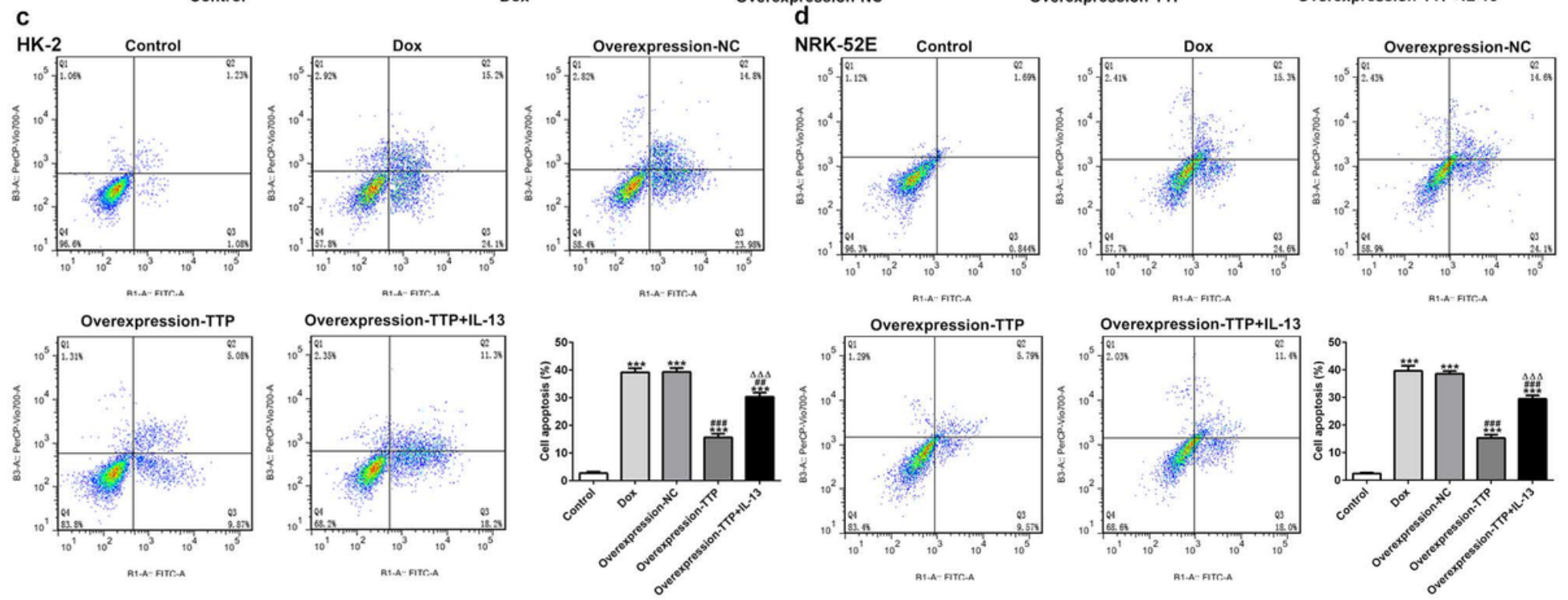

Figure 8

Effect of Tristetraprolin (TTP) on cell apoptosis in HK-2 and NRK-52E cells post DOX treatment. Morphology of (a) HK-2 and (b) NRK-52E cells stained with DAPI typical images were from one of three independent experiments. Cyanotic cells represent living cells. Apoptosis of (c) HK-2 and (d) NRK-52E cells was evaluated by Annexin V-FITC and PI staining using a flow cytometry, and percent of apoptotic cells was quantified. Numbers represent the percentage of the frequency in each quadrant. All values were expressed as means $\pm S D, n=5, * \star \star p<0.001$ vs. Control; \#\#p<0.01 and \#\#\#p<0.001 vs. DOX; $\triangle \triangle \triangle \mathrm{p}<0.001$ vs. Overexpression-TTP. 


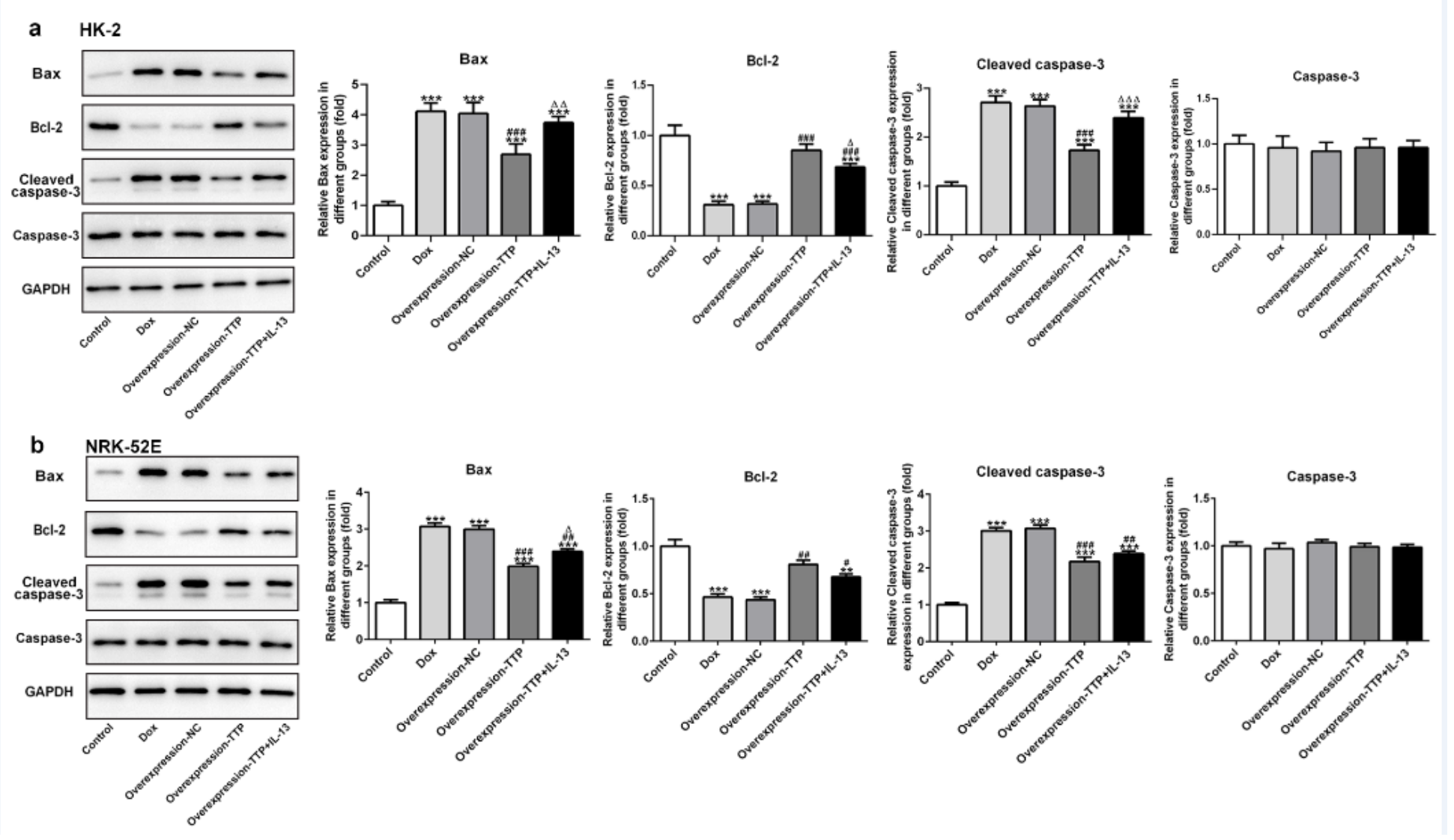

Figure 9

Effect of Tristetraprolin (TTP) on cell apoptosis markers (Bax, Bcl-2 and Caspase-3 in HK-2 and NRK-52E cells after treatment of DOX. Western blot analysis for Bax, Bcl-2, Cleaved-caspase3, Caspase 3 and the housekeeping protein GAPDH in (a) HK-2 and (b) NRK-52E cells. The bar graphs represented the relative expressions compared to GAPDH. All values were expressed as means $\pm S D, n=5,{ }^{*} p<0.01$ and

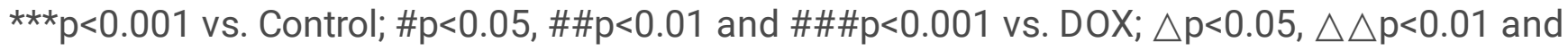
$\triangle \triangle \triangle \mathrm{p}<0.001$ vs. Overexpression-TTP. 